\title{
The effect of acute exercise session on thyroid hormone economy in rats
}

\author{
Rodrigo Soares Fortunato, Daniele Leão Ignácio, Álvaro Souto Padron, Ramon Peçanha ${ }^{1,2}$, Michelle \\ Porto Marassi, Doris Rosenthal, João Pedro Saar Werneck-de-Castro ${ }^{1,2}$ and Denise P Carvalho
}

Laboratorio de Fisiologia Endócrina Doris Rosenthal, 'aboratório de Cardiologia Celular e Molecular, Universidade Federal do Rio de Janeiro, Instituto de Biofísica Carlos Chagas Filho, Rio de Janeiro 21941-902, Brazil

${ }^{2}$ Laboratório de Biologia Muscular e do Exercício, Departamento de Biociências da Atividade Física, Universidade Federal do Rio de Janeiro, Rio de Janeiro 21949-900, Brazil

(Correspondence should be addressed to D P Carvalho who is now at CCS-Bloco G- Cidade Universitária, Ilha do Fundão, Rio de Janeiro 21949-900, Brazil; Email: dencarv@biof.ufrj.br)

\begin{abstract}
The hypothalamic-pituitary-thyroid axis is affected by acute exercise, but the mechanisms underlying thyroid function changes after exercise remain to be defined. The aim of this study was to elucidate the effects of a session of acute exercise on the treadmill at $75 \%$ of maximum oxygen consumption on thyroid function of rats. Male Wistar rats were divided into five groups: control (without exercise), and killed immediately after $(0 \mathrm{~min})$ or 30,60 , and $120 \mathrm{~min}$ after the end of the exercise session. A significant increase in serum tri-iodothyronine $\left(T_{3}\right)$ occurred immediately after the exercise, with a gradual decrease thereafter, so that $120 \mathrm{~min}$ after the end of the exercise, serum $\mathrm{T}_{3}$ was significantly lower than that in controls. Total thyroxine $\left(\mathrm{T}_{4}\right)$ increased progressively reaching values significantly higher than that in the control group at $120 \mathrm{~min} . \mathrm{T}_{3} / \mathrm{T}_{4}$ ratio was
\end{abstract}

significantly decreased 60 and $120 \mathrm{~min}$ after the exercise, indicating impaired $\mathrm{T}_{4}$-to- $\mathrm{T}_{3}$ conversion. Liver type 1 deiodinase activity (D1) significantly decreased at 60 and $120 \mathrm{~min}$, while pituitary D1 increased progressively from 30 to $120 \mathrm{~min}$ after the exercise, and thyroid D1 was increased only immediately after the end of the exercise. Brown adipose tissue (BAT) type 2 deiodinase activity (D2) was significantly lower at 30 min, but pituitary D2 remained unchanged. No change in serum thyrotropin was detected, while serum corticosterone was significantly higher $30 \mathrm{~min}$ after the exercise. Our results demonstrate that decreased liver D1 and BAT D2 might be involved in the decreased $\mathrm{T}_{4}$-to- $\mathrm{T}_{3}$ conversion detected after an exercise session on the treadmill.

Journal of Endocrinology (2008) 198, 347-353

\section{Introduction}

Thyroid hormones act on multiple metabolic processes, influencing the concentration and activity of numerous enzymes, the metabolism of substrates, vitamins and minerals, and the response of target tissues to several hormones (Larsen et al. 1992). These hormones have critical roles in cell differentiation, growth, and regulation of oxygen consumption and thermogenesis (Yen 2001). Significant changes in energy metabolism occur during the exercise and are maintained for some hours thereafter, revealing challenges for energetic homeostasis. Exercise corresponds to a physical stress followed by some endocrine modifications that occur in order to counterbalance its effects on thermogenesis and substrate metabolism (Mastorakos \& Pavlatou 2005). The influence of exercise on thyroid function is controversial and seems to depend on the intensity and duration of the training protocol (Rone et al. 1992).

The main thyroid gland hormonal secretion is thyroxine $\left(\mathrm{T}_{4}\right)$, which is then deiodinated to generate tri-iodothyronine $\left(\mathrm{T}_{3}\right)$, the most active thyroid hormone (Maia et al. 1995, Yen 2001). Types I, II, and III iodothyronine deiodinases (D1, D2, and $D 3$ respectively) regulate $T_{3}$ production and clearance via removal of specific iodine atoms from the precursor molecule $\mathrm{T}_{4}$ or $\mathrm{T}_{3}$ itself. D1 and D2 catalyze the $5^{\prime}$-deiodination of $\mathrm{T}_{4}$ and are considered activating enzymes due to subsequent $\mathrm{T}_{3}$ production. The role of $\mathrm{D} 3$ is to inactivate $\mathrm{T}_{4}$ and $\mathrm{T}_{3}$ through their 5-deiodination (Visser 1994, Bianco et al. 2002, Bianco \& Kim 2006). Thus, deiodinases can acutely regulate serum $\mathrm{T}_{4}$ and $\mathrm{T}_{3}$ levels and also their tissue availability through their activation or inactivation.

Acute and chronic exercises elicit different effects in rats: serum levels of thyroid hormones increase after acute exercise, while the same is not observed in the majority of studies with chronic exercise protocols (Mastorakos \& Pavlatou 2005). Wirth et al. (1981) observed an increase in total $\mathrm{T}_{3}$, total $\mathrm{T}_{4}$, and $\mathrm{T}_{3} / \mathrm{rT}_{3}$ ratio in rats immediately after the exercise for $20 \mathrm{~min}$ in treadmill, when compared with sedentary rats. Another study, using strenuous acute swimming exercise showed increased serum TSH levels, decreased $\mathrm{T}_{3}$ and $\mathrm{T}_{4}$ together with a blunted thyroid response to TSH stimulation immediately after the exercise protocol and a decrease in brown adipose tissue (BAT) D2 activity (Sullo et al. 2003). In humans, an acute aerobic exercise performed at $70 \%$ of 
maximum heart rate induced significant increases in total $\mathrm{T}_{3}$ and $\mathrm{T}_{4}$, free $\mathrm{T}_{3}$ and $\mathrm{T}_{4}$, and thyrotrophin (TSH); at $90 \%$ of maximum heart rate, the levels of total $\mathrm{T}_{4}$, free $\mathrm{T}_{4}$, and TSH were also increased, but serum $T_{3}$ and free $T_{3}$ decreased significantly (Ciloglu et al. 2005). Increased serum thyroid hormones immediately after the exercise might reflect catecholamine stimulation of hormonal secretion since a concerted action of the adrenergic system and the thyroid axis might correspond to an important physiological response to increased metabolic demands. On the other hand, high thermogenesis that takes place during the exercise could trigger mechanisms involved in the decrease in serum thyroid hormone levels, in order to prevent significant increases in body temperature.

These previous studies show contradictory results possibly due to the different protocols of exercise intensity used, but could also reflect differences due to the time after the exercise when the animals or humans have been evaluated. Thus, a time-course study might better define the changes that occur in the pituitary-thyroid hormone axis in exercised animals. Hence, the aim of the present study was to elucidate the effects of a session of acute exercise on thyroid function just after the exercise protocol and during the recuperation period (30, 60, and $120 \mathrm{~min}$ ). Since thyroid gland economy was affected by the exercise protocol used, we intended to further analyze proteins involved in thyroid hormone biosynthesis, as well as peripheral and central iodothyronine deiodinases, in order to try to elucidate the mechanisms involved in the changes that occur after the exercise.

\section{Materials and Methods}

\section{Experimental groups}

Adult male Wistar rats weighing 200-250 g were maintained in an animal room with controlled lighting ( $12 \mathrm{~h}$ light: $12 \mathrm{~h}$ darkness cycle) and temperature $\left(23 / 24^{\circ} \mathrm{C}\right)$. The Institutional Committee for Evaluation of Animal Use in Research (CAUAP) approved the study, according to the International Guiding Principles for Biomedical Research Involving Animals (Geneva, Switzerland). The animals were submitted to an exercise protocol that consisted of 20 min treadmill running at $75 \%$ of maximum oxygen consumption velocity $\left(\mathrm{VVO}_{2}\right)$ and a constant slope of $10^{\circ}$. To determine $\mathrm{VVO}_{2}$, the animals were adapted to run 2-3 days at $17 \mathrm{~cm} / \mathrm{s}$ during $5 \mathrm{~min}$. After the adaptation period, each rat was submitted to a maximum exercise test. We modified a ramp test for maximal treadmill running to measure the aerobic capacity of the animals (Henderson et al. 2002), as described previously (Werneck-decastro et al. 2006). Trial began at a starting velocity of $17 \mathrm{~cm} / \mathrm{s}$ and a constant slope of $10^{\circ}$. Treadmill velocity was then increased by $2 \mathrm{~cm} / \mathrm{s}$ every $2 \mathrm{~min}$ and the rats ran until exhaustion (when the animals stayed in the steel grids despite increasing stimuli shocks). Maximum velocity was considered if animals completed at least $75 \%$ of the stage. Mean room temperature was maintained at $22^{\circ} \mathrm{C}$ and a stainless steel grid at the end of the treadmill provided an electrical stimulus to keep the rats running. All tests and exercise protocol were carried out with a motor-driven treadmill chamber (Panlab - LSI Letica model, Sao Paulo, Brazil) and $\mathrm{VO}_{2}$ was measured by an oxygen analyzer (Sable Systems FC-1B O ${ }_{2}$, Las Vegas, NV, USA) at a constant flow rate of $500 \mathrm{ml} / \mathrm{min}$. $\mathrm{VO}_{2}$ consumption was obtained by the following formula: $\mathrm{VO}_{2 \max }=\left(\left(\% \mathrm{O}_{2} \max -\right.\right.$ $\% \mathrm{O}_{2}$ basal $\left./ 100\right) \times 500 \mathrm{ml} / \mathrm{min}$ ) $/$ weight $(\mathrm{kg})$ (Werneck-decastro et al. 2006).

After the experimental period, the animals were killed by decapitation and the blood was collected for hormone concentration analyses. Serum was obtained after centrifugation of the blood at $1500 \mathrm{~g}$ for $15 \mathrm{~min}$ and stored at $-20^{\circ} \mathrm{C}$. Rat tissues were dissected out, weighed, and stored in liquid nitrogen until processing for enzymatic measurements.

\section{RIA for total $T_{3}$ and $T_{4}, T S H$, and corticosterone}

The measurement of serum TSH levels was carried out using a specific RIA for rat TSH obtained from the National Institute of Diabetes, Digestive and Kidney Diseases (NIDDK, Bethesda, MD, USA), and expressed in terms of reference preparation 2 .

Serum total $\mathrm{T}_{3}$ and $\mathrm{T}_{4}$ concentrations were measured using commercial kits ( $\mathrm{T}_{3}$, DLS-3100 Active; $\mathrm{T}_{4}$, DLS-3200 Active; TX, USA), based on the presence of specific antibodies adhered to the internal surface of propylene tubes. Rat hormone-free serum was used in the standard curves for total $\mathrm{T}_{3}$ and $\mathrm{T}_{4}$ and TSH. All the procedures were carried out following the recommendations of the kit.

The levels of serum corticosterone were measured by specific RIA for rats and mice (MP Biomedicals, LLC, Solon, $\mathrm{OH}$, USA).

\section{Thyroperoxidase (TPO) iodide oxidation activity}

For extraction of TPO, each rat thyroid gland was homogenized in $50 \mathrm{mM}$ Tris- $\mathrm{HCl}$ buffer $(\mathrm{pH} 7 \cdot 2)$ and centrifuged at $200000 \mathrm{~g}, 4^{\circ} \mathrm{C}$ for $35 \mathrm{~min}$. The pellet was suspended in digitonin $\left(1 \%, \mathrm{w} / \mathrm{v}\right.$; Sigma) and stored for $24 \mathrm{~h}$ at $4{ }^{\circ} \mathrm{C}$. After this incubation period, centrifugation was repeated in the same conditions, and the supernatant containing solubilized TPO was stored at $-20^{\circ} \mathrm{C}$ (Moura et al. 1989, Carvalho et al. 1994).

TPO iodide oxidation assay (Nakashima \& Taurog 1978, Pommier 1978, Moura et al. 1989, Carvalho et al. 1994) was performed as follows: $1.0 \mathrm{ml}$ of $50 \mathrm{mM}$ sodium phosphate buffer (pH 7.4) containing $24 \mathrm{mM} \mathrm{KI}$ and $11 \mathrm{mM}$ glucose was placed in a $2 \mathrm{ml}$ cuvette; the volume of the solubilized TPO added was 10 to $100 \mu \mathrm{l}$, and the final volume was adjusted to $2 \cdot 0 \mathrm{ml}$ with $50 \mathrm{mM}$ sodium phosphate buffer $(\mathrm{pH}$ $7 \cdot 4)$. The assay was started by the addition of $10 \mu \mathrm{l}$ of $0 \cdot 1 \%$ $(\mathrm{w} / \mathrm{v})$ glucose oxidase (Boehringer Grade I). The increase in absorbance at $353 \mathrm{~nm}\left(\Delta A_{353 \mathrm{~nm}} / \mathrm{min}\right.$, triiodide formation) 
was followed for $2 \mathrm{~min}$ on a Hitachi spectrophotometer (U-3000). The $\Delta A_{353 \mathrm{~nm}} / \mathrm{min}$ was determined from the linear portion of the reaction curve and corrected for a blank determined in the absence of TPO. One unit of iodide oxidation activity is defined as $\Delta A_{353 \mathrm{~nm}} / \mathrm{min}=1 \cdot 0$. The activity was related to protein concentration in the enzyme preparation. Protein concentration was measured by the method of Bradford (1976).

\section{D1 assay}

One pituitary gland, one thyroid gland, or $25 \mathrm{mg}$ of liver were homogenized in $0 \cdot 1 \mathrm{M}$ sodium phosphate buffer containing $1 \mathrm{mM}$ EDTA, 0.25 $\mathrm{M}$ sucrose, and $10 \mathrm{mM}$ dithiothreitol $(\mathrm{pH}$ $6 \cdot 9)$. Homogenates $(150 \mu \mathrm{g}$ of protein for pituitary samples and $30 \mu \mathrm{g}$ of protein for liver and thyroid) were incubated in triplicate for $1 \mathrm{~h}$ at $37^{\circ} \mathrm{C}$ with $1 \mu \mathrm{M}\left[{ }^{125} \mathrm{I}\right] \mathrm{rT}_{3}$ (Perkin-Elmer Life and Analytical Sciences, Boston, MA, USA), and $10 \mathrm{mM}$ dithiothreitol (USB/Invitrogen) in $100 \mathrm{mM}$ potassium phosphate buffer containing $1 \mathrm{mM}$ EDTA ( $\mathrm{pH}$ 6.9) in a reaction volume of $300 \mu \mathrm{l}$, as described previously (Berry et al. 1991, Fortunato et al. 2006). Blank incubations were carried out in the absence of protein. The reaction was stopped at $4{ }^{\circ} \mathrm{C}$ in an ice bath with the addition of $100 \mu \mathrm{l}$ fetal bovine serum (Cultilab, Campinas, Brazil) and $200 \mu \mathrm{l}$ trichloroacetic acid (50\%, v/v) followed by vigorous agitation. The samples were centrifuged at $8000 \mathrm{~g}$ for $3 \mathrm{~min}$ and the supernatant was collected for the measurement of ${ }^{125}$ I liberated during the deiodination reaction. A specific D1 inhibitor (1 $\mathrm{mM}$ propylthiouracil (PTU)) was added to completely block deiodinase activity; thus, in our assay conditions, only D1 activity was measured.

D1 activity was related to the protein concentration in the homogenates. Protein concentration was measured by the method of Bradford (1976), after incubation of homogenates with $\mathrm{NaOH}(2 \cdot 5 \mathrm{M})$.

\section{D2 assay}

One pituitary gland or $25 \mathrm{mg}$ BAT were homogenized in $0 \cdot 1 \mathrm{M}$ sodium phosphate buffer containing $1 \mathrm{mM}$ EDTA, $0 \cdot 25 \mathrm{M}$ sucrose, and $10 \mathrm{mM}$ dithiothreitol ( $\mathrm{pH} \mathrm{6.9)}$. Homogenates $(50 \mu \mathrm{g}$ protein for pituitary and $150 \mu \mathrm{g}$ for BAT samples) were incubated in triplicate, $2 \mathrm{~h}$ for pituitary and $3 \mathrm{~h}$ for BAT, at $37^{\circ} \mathrm{C}$ with $1 \mathrm{nM}\left[{ }^{125} \mathrm{I}\right] \mathrm{T}_{4}$ (Perkin-Elmer Life and Analytical Sciences), $1 \mathrm{mM}$ PTU, and $20 \mathrm{mM}$ dithiothreitol (USB) in $100 \mathrm{mM}$ potassium phosphate buffer containing $1 \mathrm{mM}$ EDTA ( $\mathrm{pH} 6.9$ ) in a reaction volume of $300 \mu \mathrm{l}$, as described previously (Berry et al. 1991, Fortunato et al. 2006). Blank incubations were carried out in the absence of protein. The reaction was stopped at $4{ }^{\circ} \mathrm{C}$ in an ice bath with the addition of $100 \mu \mathrm{l}$ fetal bovine serum (Cultilab) and $200 \mu \mathrm{l}$ trichloroacetic acid (50\%, v/v) followed by vigorous agitation. The samples were centrifuged at $8000 \boldsymbol{g}$ for $3 \mathrm{~min}$ and the supernatant was collected for the measurement of ${ }^{125} \mathrm{I}$ liberated during the deiodination reaction. D2 activity was related to the protein concentration in the homogenates.
Protein concentration was measured by the method of Bradford (1976), after incubation of homogenates with $\mathrm{NaOH}(2 \cdot 5 \mathrm{M})$.

\section{Short-term radioiodide uptake: sodium-iodide symporter (NIS)} activity

We have previously demonstrated that the measurement of radioiodide uptake $15 \mathrm{~min}$ after ${ }^{125} \mathrm{I}-\mathrm{NaI}$ administration (short-term iodide uptake) reflects iodide transport through the NIS without the influence of in vivo thyroid iodine organification activity (Ferreira et al. 2005). Thus, in order to evaluate the in vivo NIS function using thyroid radioiodine uptake measurements without the influence of the TPO iodine organification reaction, the animals received $\mathrm{Na}-{ }^{125} \mathrm{I}$ (250 000 c.p.m., i.p., Amersham) 15 min before decapitation. The thyroids were removed and weighed. The radioactivity of the thyroid glands was measured using a $\gamma$-counter (LKB, Mount Waverley, Brazil) and expressed as percentage of total ${ }^{125}$ I injected per $\mathrm{mg}$ of thyroid.

\section{Statistical analyses}

The results are expressed as mean \pm s.E.M. Data from total $\mathrm{T}_{3}$, total $\mathrm{T}_{4}$, corticosterone, $\mathrm{T}_{3} / \mathrm{T}_{4}$ ratio, and deiodinase activities were analyzed by one-way ANOVA test followed by Dunnett's multiple comparison tests. The results of serum TSH, NIS, and TPO were analyzed by Kruskal-Wallis test followed by Dunnett's multiple comparison tests. Statistical analyses were done using the software GraphPad Prism (version 4, GraphPad Software, Inc., San Diego, CA, USA). $P \leq 0 \cdot 05$ was considered statistically significant.

\section{Results}

Serum total $T_{3}, T_{4}, T S H$, and corticosterone concentrations

Immediately after the exercise, a significant increase in serum total $\mathrm{T}_{3}$ was detected $(P<0.05$ versus control); however, at $30 \mathrm{~min}$ after the exercise, serum $\mathrm{T}_{3}$ returned to the basal levels and continued to decrease thereafter, reaching values that were statistically lower than controls at $120 \mathrm{~min}(P<0 \cdot 05)$ (Fig. 1A). Serum $\mathrm{T}_{4}$ was significantly higher at $120 \mathrm{~min}$ after the end of the exercise in comparison with the control and 30 min groups $(P<0 \cdot 01)$ (Fig. $1 \mathrm{~B})$. The $\mathrm{T}_{3} / \mathrm{T}_{4}$ ratio was significantly lower at $60 \mathrm{~min}$ in comparison with the control group $(P<0 \cdot 05)$ and further decreased at $120 \mathrm{~min}$, differing from all the other groups (120 min versus $C=P<0 \cdot 001$; $0=P<0 \cdot 01 ; 30=P<0 \cdot 001 ; 60 \mathrm{~min}=P<0 \cdot 05$ ) (Fig. $1 \mathrm{C}$ ). These data indicate a decrease in the $T_{4}$-to- $T_{3}$ conversion during the period of adaptation to exercise. Serum TSH did not change significantly after this acute exercise protocol (Fig. 1D). Serum levels of corticosterone were significantly higher at $30 \mathrm{~min}$ after the exercise session when compared with the control $(P<0 \cdot 05)$ and normalized thereafter (Fig. 2). 

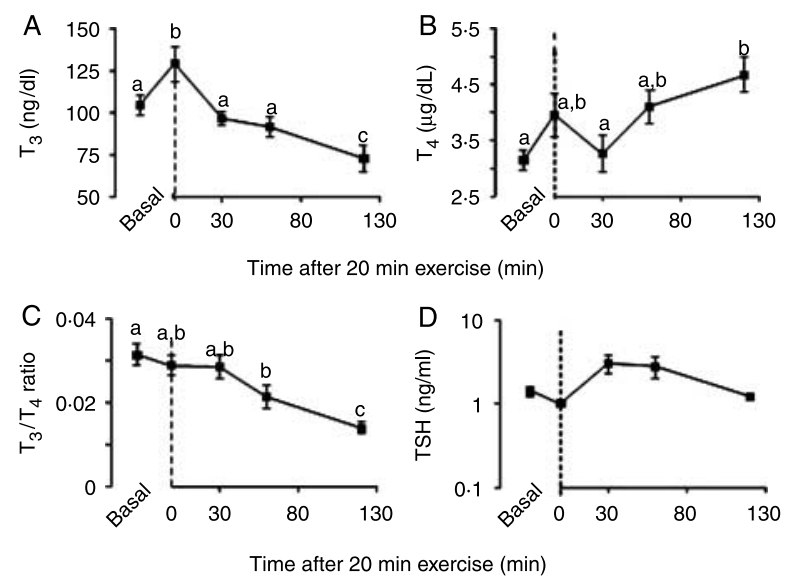

Figure 1 The effect of an acute exercise on (A) serum total $T_{3}$, (B) total $\mathrm{T}_{4},(\mathrm{C}) \mathrm{T}_{3} / \mathrm{T}_{4}$ ratio, and (D) $\mathrm{TSH}$ in different times after the protocol. The number of animals for each group was control $=12$, $0=11,30=11,60=11$, and $120=12$. Data are shown as mean \pm S.E.M.; different letters indicate statistically significant differences.

\section{TPO activity}

TPO is a key enzyme in the biosynthesis of thyroid hormones, and an alteration on its activity could account for changes in $T_{4}$ and $\mathrm{T}_{3}$ biosynthesis. Corroborating with previous findings that discard acute changes in TPO activity, the protocol of an intense acute exercise did not modify the activity of this enzyme $(C=3 \cdot 53 \pm 0 \cdot 71, n=9 ; 0 \mathrm{~min}=3 \cdot 55 \pm 0 \cdot 30, n=8$; $30 \mathrm{~min}=3 \cdot 56 \pm 0 \cdot 17, n=8 ; 60 \mathrm{~min}=4 \cdot 30 \pm 0 \cdot 38, \quad n=10$; $120 \mathrm{~min}=3 \cdot 65 \pm 0 \cdot 38 \mathrm{U} / \mathrm{mg}$ protein, $n=9)$.

\section{Short-term radioiodide uptake: NIS function}

Although the NIS function might be acutely modulated by several factors, no changes in the short-term radioiodide uptake were seen among the groups $(C=0.036 \pm 0.002, n=11$; $0 \min =0 \cdot 036 \pm 0 \cdot 003, n=12 ; 30 \mathrm{~min}=0 \cdot 036 \pm 0 \cdot 005, n=8$; $60 \min =0 \cdot 041 \pm 0 \cdot 009, n=9 ; 120 \mathrm{~min}=0 \cdot 043 \pm 0 \cdot 006 \% \mathrm{I}^{125}$

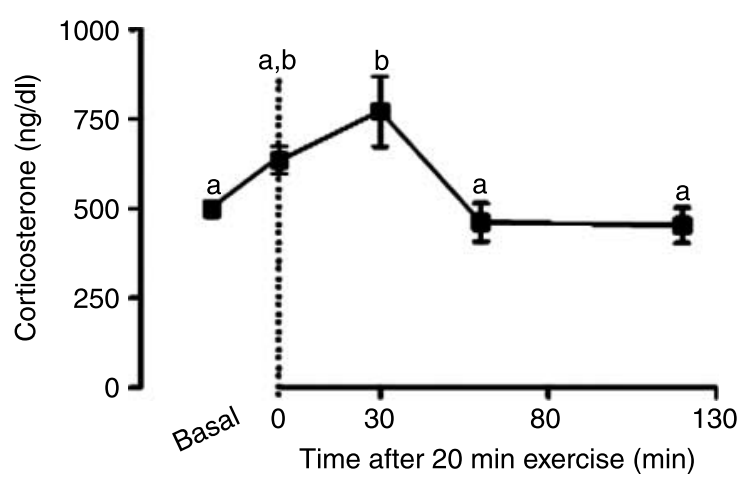

Figure 2 The effect of an acute exercise on serum corticosterone in different times after the protocol. The number of animals for each group was control $=12,0=11,30=11,60=11$, and $120=12$. Data are shown as mean \pm s.E.M.; different letters indicate statistically significant differences. per mg thyroid, $n=11)$. Since thyroid iodide uptake did not change significantly, our data indicate no functional changes in thyroid hormone biosynthesis pathways after the acute exercise protocol. $T_{3}$ increase detected immediately after the exercise might be secondary to thyroid secretion stimulation by catecholamine and/or to increased peripheral production of $\mathrm{T}_{3}$.

\section{D1 enzymatic activity}

Thyroid D1 activity was significantly increased at the end of the exercise when compared with the control group (Fig. 3C), but normalized thereafter, which could explain,
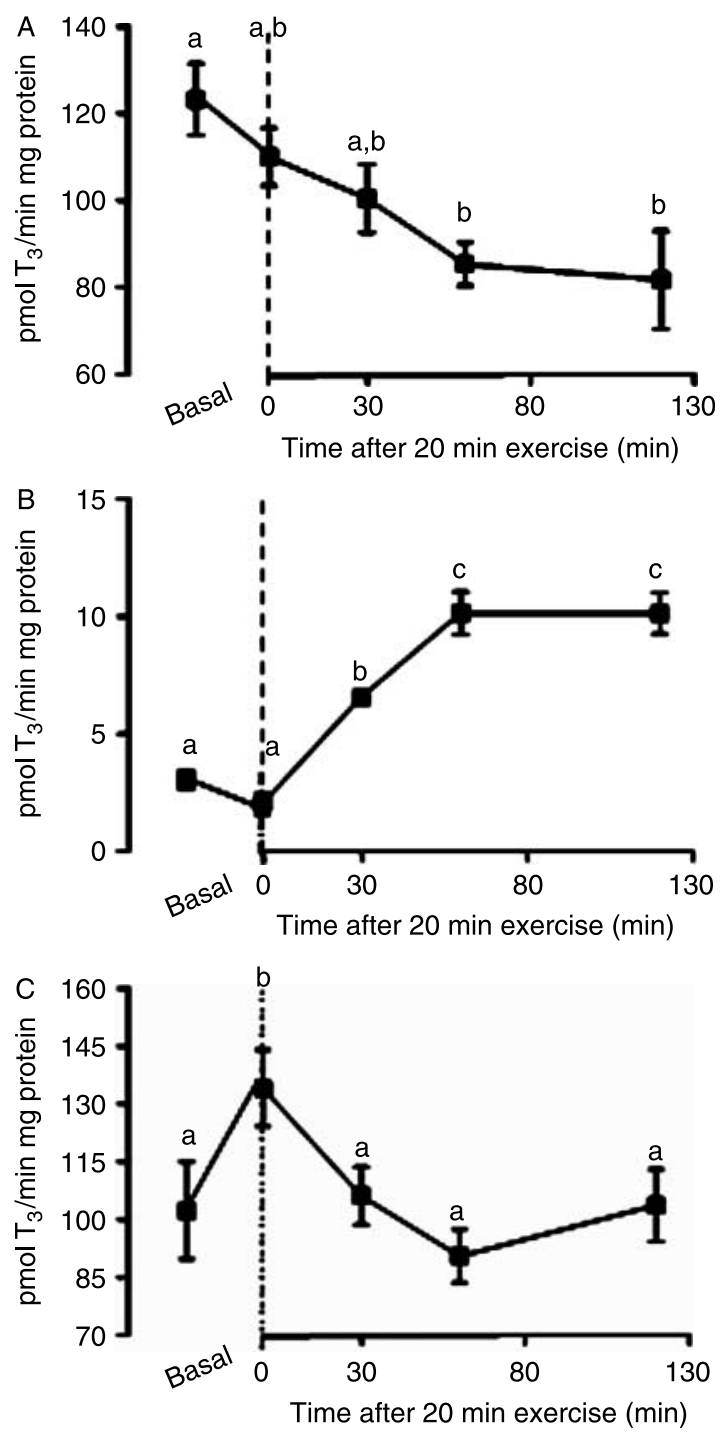

Figure 3 The effect of an acute exercise on iodothyronine deiodinase type 1 activity in (A) liver, (B) pituitary, and (C) thyroid in different times after the protocol. The number of animals for each group was control $=10,0=11,30=10,60=11$, and $120=11$. Data are shown as mean \pm s.E.M.; different letters indicate statistically significant differences. 
at least in part, the rapid increase in serum $\mathrm{T}_{3}$ observed. Immediately after the end of the exercise session, hepatic D1 activity was normal and then progressively decreased, reaching significantly lower values in comparison with the control group, at 60 and $120 \mathrm{~min}(P<0 \cdot 01)$ (Fig. 3A), a mechanism probably involved in the progressive serum $T_{3}$ decrease after the end of the exercise. Conversely, pituitary D1 activity significantly increased at 30,60, and $120 \mathrm{~min}$ in comparison with the control $(P<0 \cdot 01)$ and 0 min groups $(P<0 \cdot 001)$; at 60 and $120 \mathrm{~min}$, pituitary D1 was also significantly increased when compared with $30 \mathrm{~min}$ (Fig. 3B).

\section{D2 enzymatic activity}

BAT D2 activity decreased significantly $30 \mathrm{~min}$ after the end of the exercise session, when compared with control $(P<0 \cdot 01), 0 \quad(P<0 \cdot 05)$ and $120 \mathrm{~min}$ group $(P<0 \cdot 001)$. BAT D2 activity was only restored to the control levels 120 min after the end of the exercise $(P<0 \cdot 01)$ (Fig. 4A). Pituitary D2 activity did not change significantly (Fig. 4B). The decrease in BAT D2 activity could also contribute to the decreased serum $\mathrm{T}_{3}$ after the exercise.
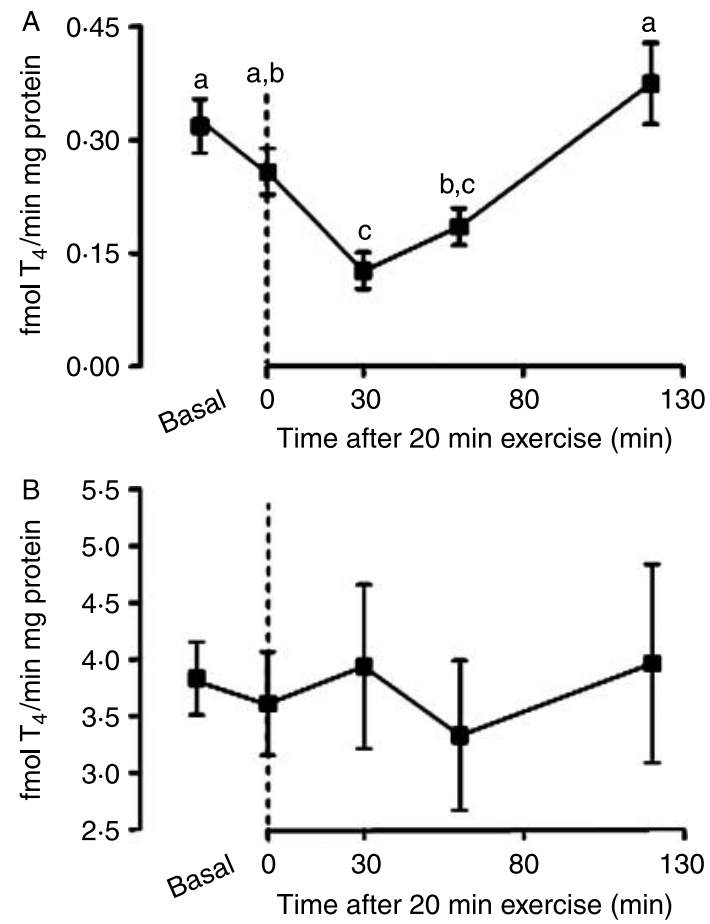

Figure 4 The effect of an acute exercise on iodothyronine deiodinase type 2 activity on (A) brown adipose tissue and (B) pituitary in different times after the protocol. The number of animals for each group for BAT was control $=10,0=10,30=9,60=11$, $120=9$, and for pituitary was $n=6$ for all groups. Data are shown as mean \pm s.E.M.; different letters indicate statistically significant differences.

\section{Discussion}

Exercise is a stressful situation that challenges body homeostasis, so that the organism has to reestablish a new dynamic equilibrium in order to minimize cell damage. One of the systems affected is the hypothalamic-pituitary-thyroid axis (Mastorakos \& Pavlatou 2005). While increased metabolic demands occur during exercise, higher thermogenesis is counterbalanced by mechanisms that are activated in order to dissipate heat-like vasodilatation. Both metabolism of substrates and thermogenesis are tightly regulated by thyroid hormones, and we show herein some of the mechanisms involved in thyroid function alterations that occur immediately after the exercise and for some hours thereafter. The intensity, duration, and type of exercise may elicit different patterns of response, and thus the results obtained are contradictory. The utilization of experimental animals to clarify these questions is useful to discard variables that are commonly found in human subject studies, apart from the possibility of studying the mechanisms involved in the hormonal changes observed.

In our study, the rats were submitted to an exercise session at $75 \%$ of maximal oxygen consumption, during $20 \mathrm{~min}$, and the thyroid function was assessed immediately after and 30 , 60 , and $120 \mathrm{~min}$ after the end of the exercise protocol. Serum total $T_{3}$ levels were significantly higher immediately after the end of the exercise, while serum total $\mathrm{T}_{4}$ and TSH levels were not altered. These findings are in agreement with the results found by Límanová et al. (1983), in a study with untrained young subjects, and those by Wirth et al. (1981), who showed an association of increased $\mathrm{T}_{3}$ with an augmented norepinephrine response (Wirth et al. 1981, Límanová et al. 1983). Increased serum $T_{3}$ immediately after the end of an acute exercise session is probably caused by the adrenergic stimulus that occurs during the exercise, since exercise protocols at $60 \%$ of maximum oxygen capacity or greater are accompanied by large increases in circulating catecholamine levels, and the ability of adrenergic stimulus to increase basal thyroid hormone secretion is well established (Ahren et al. 1986, Coggan et al. 2000). However, in other studies, the levels of $T_{3}, T_{4}$, and TSH at the end of the exercise were unaffected or decreased by the exercise protocol. While Sullo et al. (2003) found a decrease in serum total $\mathrm{T}_{3}$ and $\mathrm{T}_{4}$ concentrations and an increase in TSH in rats at the end of a strenuous swim exercise. Krotkiewski et al. (1984) in a study with obese women showed no changes in these hormone levels. The divergence among these works is probably due to the different exercise protocols executed, as we know that catecholamine secretion depends on the intensity and duration of exercise.

TPO and NIS are two important proteins involved in the biosynthesis of thyroid hormones; while TPO is the enzyme that catalyzes the formation of $\mathrm{T}_{3}$ and $\mathrm{T}_{4}$, NIS is a symporter that transports two sodium ions along with one iodide into the follicular thyroid cell (Carvalho et al. 1994, 
Eskandari et al. 1997). In our study, exercise had no effect on TPO and the NIS function. This is the first report evaluating the effect of acute exercise on these parameters. RosolowskaHuszcz (1998) studied the effect of different intensities of 5 -week exercise in rats and have shown a decrease in TPO activity at the higher intensities (Rosołowska-Huszcz 1998). The primary hormonal stimulator of TPO and NIS is TSH (Gerard et al. 1988, Uyttersprot et al. 1997, Ferreira et al. 2005). Serum TSH was not acutely modulated by the exercise protocol used herein, and the activities of TPO and NIS did not change, discarding a possible acute effect of catecholamines or other hormonal regulators on these parameters after intense acute exercise.

Krotkiewski et al. (1983) evaluated the changes in thyroid hormones at 30,60, and $90 \mathrm{~min}$ after the end of the exercise in obese women and have shown a progressive decrease in serum TSH along with a progressive increase in serum total $\mathrm{T}_{4}$, with no significant changes in serum $\mathrm{T}_{3}$ levels. In our study, the levels of serum $\mathrm{T}_{3}$ progressively decreased after the end of the exercise, reaching values 30\% lower than control levels $2 \mathrm{~h}$ after the end of the exercise, while serum $\mathrm{T}_{4}$ increased progressively, indicating impaired $\mathrm{T}_{4}$-to- $\mathrm{T}_{3}$ conversion after the end of the exercise.

The $\mathrm{T}_{4}$-to- $\mathrm{T}_{3}$ conversion is catalyzed by iodothyronine deiodinase types 1 and 2 (D1 and D2 respectively). It is believed that about $80 \%$ of circulating $\mathrm{T}_{3}$ is formed from the $\mathrm{T}_{4}$ molecule. Type 1 iodothyronine deiodinase enzyme (D1) that is widely expressed in tissues such as liver, kidney, thyroid, and pituitary provides part of the plasma $T_{3}$ through the $5^{\prime}$-deiodination of the $\mathrm{T}_{4}$ molecule (Bianco et al. 2002). In rats, the extra-thyroidal deiodination reaction is responsible for about $60 \%$ of the circulating $\mathrm{T}_{3}$, and both peripheral D1 and D2 seem to equally contribute to $T_{3}$ generation, while the remaining $40 \%$ come from thyroid secretion (Bianco et al. 2002). There are few studies about the regulation of deiodinases after acute exercise, but no time-course studies showing the activity of these enzymes after an acute exercise protocol have been reported so far.

As we show herein, the increased serum $T_{3}$ that occurs immediately after the exercise is accompanied by a significant increase in thyroid D1 activity, an enzyme that is involved in thyroid $\mathrm{T}_{4}$-to- $\mathrm{T}_{3}$ conversion. Liver D1 activity progressively decreased after the end of the exercise protocol, and BAT D2 activity was significantly reduced at $30 \mathrm{~min}$ after the exercise. At $30 \mathrm{~min}$ after the end of the exercise, serum corticosterone levels reached its maximum concentration. It is known that plasma glucocorticoids can decrease liver D1 activity (Bianco et al. 2002). Both the decrease in BAT D2 at $30 \mathrm{~min}$ and decreased liver D1 might contribute to the lower serum $\mathrm{T}_{3}$ levels during the recuperation period after the exercise.

A previous report has described decreased BAT D2 activity in rats acutely submitted to a strenuous swimming protocol (Sullo et al. 2003). In our study, BAT D2 activity decreased $30 \mathrm{~min}$ after the end of the exercise, but at $120 \mathrm{~min}$ its activity was restored. It is noteworthy that BAT D2 is up-regulated by catecholamines during cold exposure, but its regulation in BAT seems to be far more complex (Obregon et al. 1987). Cold exposure significantly increases D2 activity by the adrenergic pathway, but ob/ob mice that have high serum corticosterone levels show defective induction of BAT D2 during cold acclimation (Kates \& Himms-Hagen 1990). In our study, $30 \mathrm{~min}$ after the exercise protocol, we detected low BAT D2 activity and high serum corticosterone levels. Corticosterone levels normalized after $60 \mathrm{~min}$, and BAT D2 activity also returned to the normal value, suggesting a negative regulation of D2 by corticosterone notwithstanding high catecholamine stimulus. Since BAT D2 plays an important role in the intracellular $\mathrm{T}_{4}$-to- $\mathrm{T}_{3}$ conversion, the decrease in D2 during the exercise recuperation period is probably important for the control of BAT thermogenesis after the exercise.

Pituitary D1 activity increased $30 \mathrm{~min}$ after the exercise and remained high until $120 \mathrm{~min}$. Since somatotrophs express high D1 activity and correspond to $\sim 50 \%$ of the pituitary cell population, the induction of pituitary D1 might reflect the activation of this cell type during the exercise. However, further studies are needed in order to evaluate the importance of pituitary D1 activation on the stimulation of GH secretion that might occur after the exercise.

In conclusion, we show herein that serum thyroid hormone changes that follow an acute exercise protocol seem to be mainly due to the regulation of both thyroid and liver D1 and BAT D2. The understanding of iodothyronine deiodinases regulation by corticosterone and adrenaline, as well as by other mediators induced by exercise, is of great interest in order to clarify their physiological role after an acute exercise protocol.

\section{Declaration of Interest}

The authors declare that there is no conflict of interest that could be perceived as prejudicing the impartiality of the research reported.

\section{Funding}

This work was supported by the grants from Fundação Carlos Chagas Filho de Amparo à Pesquisa do Estado do Rio de Janeiro (FAPERJ), Programa de Núcleos de Excelência (PRONEX/CNPq), Conselho Nacional de Desenvolvimento Científico e Tecnológico (CNPq), and Coordenação de Aperfeiçoamento de Pessoal de Nível Superior (CAPES). R S F is a recipient of a fellowship from CNPq, D L I from CAPES, and Á S P from FAPERJ.

\section{Acknowledgements}

We are grateful for the technical assistance of Norma Lima de Araújo Faria, Advaldo Nunes Bezerra, and Wagner Nunes Bezerra.

\section{References}

Ahren B, Bengtsson HI \& Hedner P 1986 Effects of norepinephrine on basal and thyrotropin-stimulated thyroid hormone secretion in the mouse. Endocrinology 119 1058-1062. 
Berry MJ, Banu L \& Larsen PR 1991 Selenocysteine confers the biochemical properties of the type 1 iodothyronine deiodinase. Journal of Biological Chemistry 266 14155-14158.

Bianco AC \& Kim BW 2006 Deiodinases: implications of the local control of thyroid hormone action. Journal of Clinical Investigation 116 2571-2579.

Bianco AC, Salvatore D, Gereben B, Berry MJ \& Larsen PR 2002 Biochemistry, cellular and molecular biology, and physiological roles of the iodothyronine selenodeiodinases. Endocrine Reviews 23 38-89.

Bradford MM 1976 A rapid and sensitive method for the quantitation of microgram quantities of protein utilizing the principle of protein-dye binding. Analytical Biochemistry 72 248-254.

Carvalho DP, Rego KGM \& Rosenthal D 1994 Thyroid peroxidase in dyshormonogenetic goiters with organification and thyroglobulin defects. Thyroid 4 421-426.

Ciloglu F, Peker I, Pehlivan A, Karacabey K, Ilhan N, Saygin O \& Ozmerdivenli R 2005 Exercise intensity and its effects on thyroid hormones. Neuro Endocrinology Letters 26 830-834.

Coggan AR, Raguso CA, Gastaldelli A, Sidossis LS \& Yeckel CW 2000 Fat metabolism during high-intensity exercise in endurance-trained and untrained men. Metabolism 49 122-128.

Eskandari S, Loo DD, Dai G, Levy O, Wright EM \& Carrasco N 1997 Thyroid $\mathrm{Na}^{+} / \mathrm{I}^{-}$symporter. Mechanism, stoichiometry, and specificity. Journal of Biological Chemistry 272 27230-27238.

Ferreira ACF, Lima LP, Araújo RL, Müller G, Rocha RP, Rosenthal D \& Carvalho DP 2005 Rapid regulation of the thyroid sodium-iodide symporter (NIS) activity by thyrotropin, iodine and fasting. Journal of Endocrinology 184 69-76.

Fortunato RS, Marassi MP, Chaves EA, Nascimento JH, Rosenthal D \& Carvalho DP 2006 Chronic administration of anabolic androgenic steroid alters murine thyroid function. Medicine and Science in Sports and Exercise 38 256-261.

Gerard CM, Lefort A, Libert F, Christophe D, Dumont JE \& Vassart G 1988 Transcriptional regulation of the thyroperoxydase gene by thyrotropin and forskolin. Molecular and Cellular Endocrinology 60 239-242.

Henderson KK, Wagner H, Favret F, Britton SL, Koch LG, Wagner PD \& Gonzalez NC 2002 Determinants of maximal $\mathrm{O}_{2}$ uptake in rats selectively bred for endurance running capacity. Journal of Applied Physiology $\mathbf{9 3}$ $1265-1274$.

Kates AL \& Himms-Hagen J 1990 Defective regulation of thyroxine $5^{\prime}$-deiodinase in brown adipose tissue of ob/ob mice. American Journal of Physiology 258 E7-E15.

Krotkiewski M, Sjöström L, Sullivan L, Lundberg PA, Lindstedt G, Wetterqvist H \& Björntorp P 1984 The effect of acute a chronic exercise on thyroid hormones in obesity. Acta Medica Scandinavica 216 269-275.

Larsen PR, Davies TF \& Hay ID 1992 The thyroid gland. In Williams Textbook of Endocrinology, 8 edn, p 409. Eds JD Wilson \& DW Foster. Philadelfia: W.B. Saunders Company.

Límanová Z, Sonka J, Kratochvíl O, Sonka K, Kanka J \& Sprynarová S 1983 Effects of exercise on serum cortisol and thyroid hormones. Experimental and Clinical Endocrinology 81 308-314.
Maia AL, Berry MJ, Sabbag R, Harney JW \& Larsen PR 1995 Structural and functional differences in the dio1 gene in mice with inherited type 1 deiodinase deficiency. Molecular Endocrinology 9 969-980.

Mastorakos G \& Pavlatou M 2005 Exercise as a stress model and the interplay between the hypothalamus-pituitary-adrenal and the hypothalamuspituitary-thyroid axes. Hormone and Metabolic Research 37 577-584.

Moura EG, Rosenthal D \& Carvalho-Guimarães DP 1989 Thyroid peroxidase activity in human nodular goiters. Brazilian Journal of Medical and Biological Research 22 31-39.

Nakashima T \& Taurog A 1978 Improved assay procedures for thyroid peroxidase; applications to normal and adenomatous human thyroid tissue. Clinica Chimica Acta 83 129-140.

Obregon MJ, Mills I, Silva JE \& Larsen PR 1987 Catecholamine stimulation of iodothyronine $5^{\prime}$-deiodinase activity in rat dispersed brown adipocytes. Endocrinology 120 1069-1072.

Pommier J 1978 Solubilization, purification, propriétés moleculaires et mécanisme d'action de la peroxidase thyroidienne. In Méthodologie Experimentale en Physiologie et Physiopathologie Thyroidienne, pp 137. -148. Eds R Hornek \& J Nunez. Paris: INSERM.

Rone JK, Dons RF \& Reed HL 1992 The effect of endurance training on serum triiodothyronine kinetics in man: physical conditioning marked by enhanced thyroid hormone metabolism. Clinical Endocrinology 37 325-330.

Rosołowska-Huszcz D 1998 The effect of exercise training intensity on thyroid activity at rest. Journal of Physiology and Pharmacology 49 457-466.

Sullo A, Brizzi G \& Maffulli N 2003 Deiodinating activity in the brown adipose tissue of rats following short cold exposure after strenuous exercise. Physiology and Behavior 80 399-403.

Uyttersprot N, Pelgrims N, Carrasco N, Gervy C, Maenhaut C, Dumont JE \& Miot F 1997 Moderate doses of iodide in vivo inhibit cell proliferation and the expression of thyroperoxidase and $\mathrm{Na}^{+} / \mathrm{I}^{-}$symporter mRNAs in $\operatorname{dog}$ thyroid. Molecular and Cellular Endocrinology 131 195-203.

Visser TJ 1994 Role of sulfation in thyroid hormone metabolism. ChemicoBiological Interactions 92 293-303.

Werneck-de-Castro JP, Costa-E-Sousa RH, de Oliveira PF, Pinho-Ribeiro V, Mello DB, Pecanha R, Mattos E, Olivares EL, Maia AC, Mill JG et al. 2006 G-CSF does not improve systolic function in a rat model of acute myocardial infarction. Basic Research in Cardiology 101 494-501.

Wirth A, Holm G, Lindstedt G, Lundberg PA \& Bjorntorp P 1981 Thyroid hormones and lipolysis in physically trained rats. Metabolism 30 237-241.

Yen PM 2001 Physiological and molecular basis of thyroid hormone action. Physiological Reviews 81 1097-1126.

Received in final form 27 May 2008

Accepted 4 June 2008

Made available online as an Accepted Preprint 5 June 2008 